\title{
Wheat bran- but not oat bran-enriched diets increase the mucosal height of the cecum and colon of newly weaned and aged rats
}

\section{C.R. Cavaglieri-Felippe², M.L.O. Polacow ${ }^{2}$, M.R. Campos ${ }^{2}$,} M.G. Vecchia ${ }^{2}$ and R. Curi ${ }^{1}$
${ }^{1}$ Departamento de Fisiologia e Biofísica, Instituto de Ciências Biomédicas, Universidade de São Paulo, 05508-900 São Paulo, SP, Brasil

2Departamento de Ciências Biológicas, Universidade Metodista de Piracicaba, 13400-901 Piracicaba, SP, Brasil

\section{Correspondence}

R. Curi

Laboratório de Fisiologia Celular

Departamento de Fisiologia

e Biofísica, ICB, USP

Av. Prof. Lineu Prestes, 1524

05508-900 São Paulo, SP

Brasil

Fax: 55 (011) 818-7285

E-mail: ruicuri@bmb.icb1.usp.br

Research supported by FAPESP (No. 93/3498-4), FAP-UNIMEP and CNPq.

Received October 18, 1996 Accepted June 13, 1997

\begin{abstract}
The effect of diets enriched with oat or wheat bran (prepared by the addition of $300 \mathrm{~g}$ of each fiber to $1000 \mathrm{~g}$ of the regular diet), given for 8 weeks, on the mucosal height of the colon and cecum was investigated. Newly weaned ( 21 days old) and aged (12 months old) male Wistar rats were used in this study. As compared to controls, diets enriched with wheat bran provoked a significant increase in the mucosal height, whereas oat bran did not cause any effect. In newly weaned rats (21 days old), wheat bran increased the mucosal height $(\mu \mathrm{m})$ in the cecum by $20 \%$ (mean \pm SEM for 8 rats; $169.1 \pm 5.2$ and $202.9 \pm 8.0$ for control and wheat bran, respectively) and in the colon $(218.8 \pm 7.2$ and $264.5 \pm 18.8$ for control and wheat bran, respectively). A similar effect was observed in aged rats (12 months old), with an increase of $15 \%$ in the mucosal height $(\mu \mathrm{m})$ of the cecum (mean \pm SEM of 8 rats; $193.2 \pm 8.6$ and $223.7 \pm 8.3$ for control and wheat bran, respectively) and of $17 \%$ in the colon (300.4 \pm 9.2 and $352.2 \pm 15.9$ for control and wheat bran, respectively).
\end{abstract}

\section{Introduction}

The greatest protection associated with high fiber intake is that against gastrointestinal disorders. In 1980, the Royal College of Physicians (1) reviewed the potential protective role of fibers against gallstones, functional bowel disorders, diverticular disease of the colon, colon cancer, appendicitis, hemorrhoids, and hiatal hernia. Although a full link between these conditions and fiber-depleted diets has not been established, popu-
Key words

- Oat bran

- Wheat bran

- Colon

- Cecum

- Mucosa

- Ageing lations with a high fiber intake have a lower incidence of these gastrointestinal disorders.

Total parenteral nutrition or the administration of a fiber-free liquid diet leads to colonic atrophy (2). The addition of fibers to a fiber-free defined diet increases colonic DNA synthesis and DNA content as well as mucosal weight (3). The response of the mucosa to fibers is assumed to occur due to the bulk effect (4) and to fermentation to short-chain fatty acids (SCFA; acetic, propionic, and butyric acids) (5). In fact, Pell et al. 
(6) postulated that dietary fiber has a viscosity-related trophic effect in the small bowel and a fermentation-related trophic effect in the colon. SCFA are mainly produced by fermentation of water-soluble fibers and play a role as a metabolic fuel for the colon (5), stimulate mucosal proliferation (7), and increase sodium and water absorption (8). Because the generation of SCFA has been assumed to be the main mechanism for the intestinal function of fibers, a number of studies have been developed to examine the effect of these acids on cell proliferation and differentiation. Butyrate provokes a marked inhibition of the growth of several tumor cell lines in culture (9). A recent study from our laboratory has shown that propionate, at concentrations ranging from 1 to $5 \mathrm{mM}$, also inhibits the proliferation of tumor (HeLa155 and KB-172) and normal (MA-104) cell lines in vitro (10). In addition, propionate

Table 1 - Basic composition of the regular diet

\begin{tabular}{ll}
\hline Protein & $18 \%$ \\
Fat & $4.0 \%$ \\
Carbohydrates & $45.5 \%$ \\
Minerals & $8.0 \%$ \\
Insoluble fiber & $18.0 \%$ \\
Soluble fiber & $3.9 \%$ \\
Calcium & $1.8 \%$ \\
Phosphorus & $0.8 \%$ \\
& \\
Vitamin mixture (expressed by kg of diet) \\
Vit A & $20,000 \mathrm{IU}$ \\
Vit D3 & $6,600 \mathrm{IU}$ \\
Vit E & $30.0 \mathrm{mg}$ \\
Vit K & $6.0 \mathrm{mg}$ \\
Vit B12 & $10.0 \mathrm{mg}$ \\
Vit B2 & $8.0 \mathrm{mg}$ \\
Niacin & $95.0 \mathrm{mg}$ \\
Pantothenic acid & $24.0 \mathrm{mg}$ \\
Thiamin & $4.0 \mathrm{mg}$ \\
Choline & $2,000 \mathrm{mg}$ \\
Pyridoxine & $6.0 \mathrm{mg}$ \\
Biotin & $0.1 \mathrm{mg}$ \\
Folic acid & $0.5 \mathrm{mg}$ \\
Manganese & $50.0 \mathrm{mg}$ \\
lodine & $2.0 \mathrm{mg}$ \\
Iron & $65.0 \mathrm{mg}$ \\
Zinc & $35.0 \mathrm{mg}$ \\
Copper & $26.0 \mathrm{mg}$ \\
Antioxidant & $100.0 \mathrm{mg}$ \\
&
\end{tabular}

has been shown to stimulate lymphocyte proliferation at low concentrations $(40 \mu \mathrm{M}$ and $0.1 \mathrm{mM}$ ) but to inhibit it at concentrations above $1 \mathrm{mM}$ (11). Intracolonic infusion of SCFA increases mucosal weight and the protein and DNA content of the proximal colon (12). Experiments carried out on parenterally nourished rats have shown that SCFA infusion into the colon promotes a modest increase in mucosal height and mucosal DNA content but does not influence absorption (13).

In spite of the reports mentioned above, it is not known whether the effect of a watersoluble fiber-enriched diet (the main source of SCFA) on the mucosa of the large bowel is more pronounced than that of an insoluble fiber-enriched diet. In the present study, we determined the effect of fiber-rich diets on the mucosal height of the colon and cecum. Rats received two types of fiber-rich diets presenting different soluble/insoluble ratios for 8 weeks, i.e., oat bran (0.3) and wheat bran (0.14). To better characterize the effect of the fiber-rich diets on the intestinal mucosa, the experiments were carried out on newly weaned (21 days old) and aged (12 months old) rats.

\section{Material and Methods}

\section{Animals and diet preparation}

Newly weaned (21 days old) male Wistar rats weighing 50-60 $\mathrm{g}$ and aged rats (12 months old) weighing 310-330 g were obtained from the Animal House of the Institute of Biomedical Sciences, USP, São Paulo. During the experiment, the rats were kept in groups of 5 animals at $23^{\circ} \mathrm{C}$ on a 12-h light/ 12-h dark cycle (lights on at 7:00 a.m.). Newly weaned and aged rats were divided into three groups: 1) control rats were fed a regular diet whose composition is shown in Table 1,2) the oat bran-enriched diet was prepared by the addition of $300 \mathrm{~g}$ of oat bran to $1000 \mathrm{~g}$ of the regular diet, and 3) the wheat 
bran-enriched diet was prepared by the addition of $300 \mathrm{~g}$ of wheat bran to $1000 \mathrm{~g}$ of the regular diet. The soluble/insoluble fiber ratio was $0.22,0.30$ and 0.14 for control, oat bran and wheat bran-enriched diets, respectively. During the 8 weeks on the respective diets, body weight, daily food intake and feces elimination were evaluated weekly. After this period, now mature (previously called newly weaned) and aged rats were killed by decapitation without anesthesia and the colon and cecum were removed. The experiments were always carried out between 8:00 and 11:00 h.

\section{Measurement of mucosal height of the colon and cecum}

Segments of the cecum and colon were kept in $10 \%$ formalin solution and processed for paraffin embedding, and 7- $\mu$ m thick slices were stained with hematoxylin-eosin. The height of the cecum and colon mucosa was determined in 8 rats, 3 sections per rat, and 10 different areas per section. The mucosal height was measured in areas formed by a single cell layer with the base of the crypt being in direct contact with the muscular mucosa. All measurements were carried using an ocular micrometer (Ernest Leitz, Wetzpar, Germany).

\section{Statistical analysis}

Data were analyzed statistically by ANOVA and by the Student $t$-test. The level of significance was set at $\mathrm{P}<0.05$.

\section{Results}

The body weight gain of mature rats fed the oat bran-enriched diet did not differ from the control group. However, the body weight of mature rats fed the wheat bran-enriched diet was $18 \%$ lower than control at the end of the 8-week period (data not shown). The body weight gain of aged rats was not modi-
Table 2 - Effect of soluble (oat bran) and insoluble (wheat bran) fiber-rich diets on the mucosal height of colon and cecum of mature and aged rats.

For details of diet preparation and measurement of the mucosal height see Material and Methods. Data are reported as the mean \pm SEM of 8 rats. ${ }^{*} P<0.05$ compared to the control group (Student $t$-test).

\begin{tabular}{lccc}
\hline \multicolumn{4}{c}{ Mucosal height $(\mu \mathrm{m})$} \\
\cline { 2 - 4 } & Control & Oat bran & Wheat bran \\
\hline Mature rats & & & \\
$\quad$ Cecum & $169.1 \pm 5.2$ & $165.5 \pm 3.0$ & $202.9 \pm 8.0^{*}$ \\
Colon & $218.8 \pm 7.2$ & $233.2 \pm 10.5$ & $264.5 \pm 18.8^{*}$ \\
Aged rats & & & \\
Cecum & $193.2 \pm 8.6$ & $188.2 \pm 11.1$ & $223.7 \pm 8.3^{*}$ \\
Colon & $300.4 \pm 9.2$ & $267.8 \pm 13.3$ & $352.2 \pm 15.9^{*}$
\end{tabular}

fied by either fiber-rich diet. Daily food intake and feces dry weight did not differ between groups $(\mathrm{P}<0.05)$.

The wheat bran-enriched diet provoked a significant increase in mucosal height, whereas oat bran did not cause any effect compared to control (Table 2). In mature rats, wheat bran increased the mucosal height in cecum and colon by $20 \%$. A similar effect was observed in aged rats, with an increase of $15 \%$ in the cecum and of $17 \%$ in the colon. Photomicrographs of cecum and colon mucosa provide additional evidence of these findings (portions 3 and 6 of Figures 1 and 2).

\section{Discussion}

Volatile short-chain fatty acids are the major solute fraction of fecal water produced by fermentation of fibers by anaerobic bacteria normally residing in the large bowel (14). These fatty acids are known to have a trophic effect on the large bowel and the response to the different fibers suggests that the more readily fermentable fibers have the greatest effect (6). Several studies have presented evidence that acetate, propionate and mainly butyrate raise DNA synthesis in the 


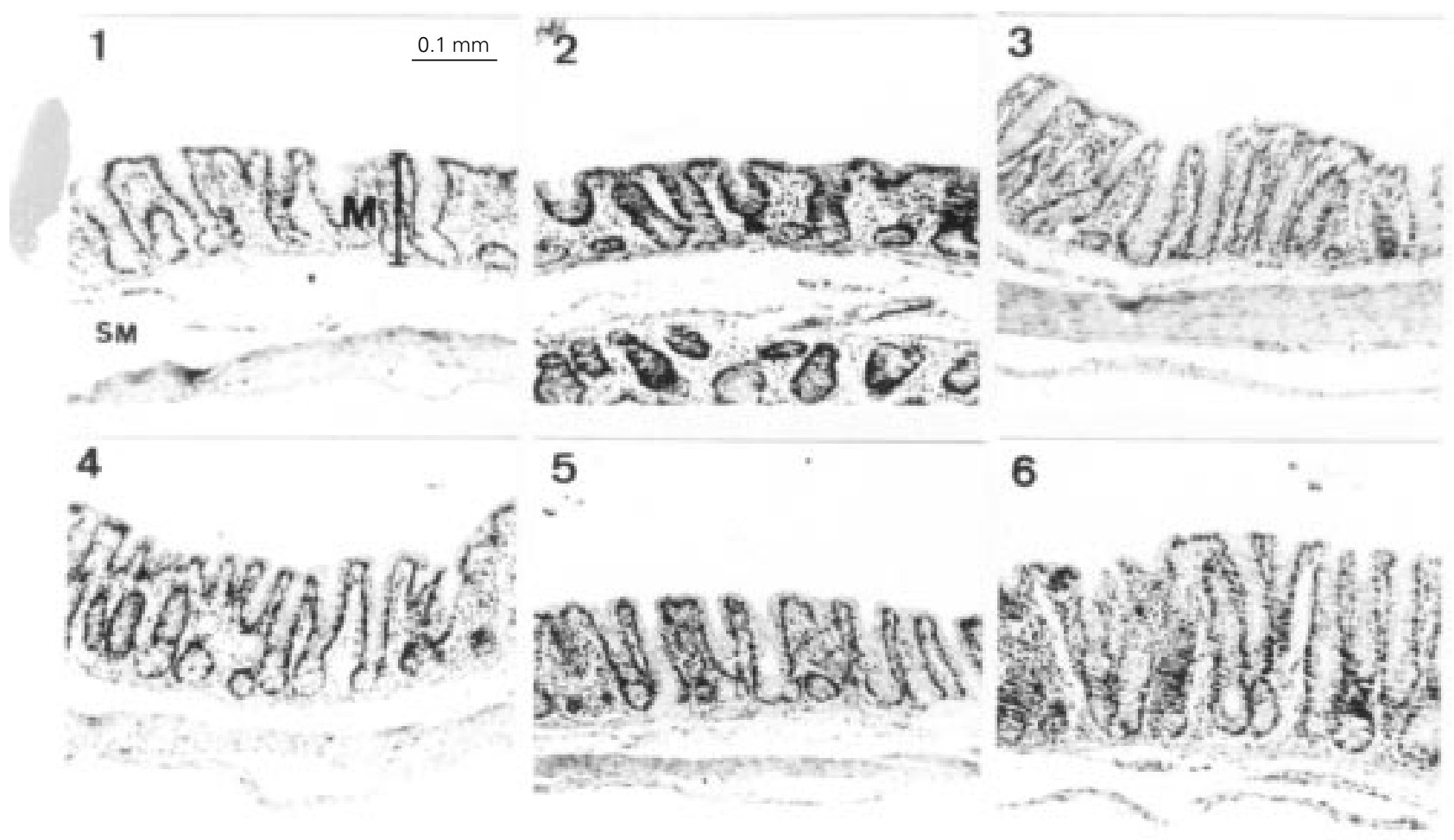

Figure 1 - Photomicrographs of the cecum mucosa from mature (1,2 and 3) and aged (4, 5 and 6$)$ rats fed a control diet (1 and 4$)$ or diets enriched with oat bran (2 and 5) or wheat bran ( 3 and 6). The tissues were prepared as described in Material and Methods and stained with hematoxylin and eosin (X100). The mucosal height is indicated by the vertical bar. The horizontal magnification bar corresponds to $0.1 \mathrm{~mm}$. M, Mucosa; SM, submucosa.

intestinal mucosa (15). In addition, these SCFA are also fuels for these cells (5) and this fact might be important in the control of epithelial cell proliferation. In spite of this, however, there are several trophic factors which can effectively control the maintenance of the intestinal epithelium such as 1) blood flow to the tissue $(16), 2)$ motility of the intestine (17), 3) trophic hormones such as enteroglucagon (18), 4) conditions of the lumen such as the presence of biliary salts (19), and 5) amines produced by bacteria metabolism.

The stimulating effect of the SCFA on cell proliferation should be considered with concern. In fact, there is evidence that these fatty acids are potent inhibitors of cell proliferation at high concentrations. Butyrate has been shown to reduce tumor development (9) and to promote apoptosis of colonic carcinoma cells $(20,21)$ and of the myeloid HL-
60 cell line (22). Also, the development of colorectal cancer has been inversely correlated with the amount of butyric acid in the feces (23). Propionate stimulates lymphocyte proliferation at concentrations up to 1 $\mathrm{mM}$ but provokes a marked inhibition at concentrations above $2 \mathrm{mM}$ (11). This SCFA also inhibits the proliferation of several tumor cell lines (10). Several mechanisms have been postulated to be involved in the control of cell proliferation by SCFA such as inhibition of oncogene expression $(24,25)$, stimulation of polyamine biosynthesis (26) and reduction of lipid synthesis (27).

The production of SCFA in the gastrointestinal tract results mainly from watersoluble dietary fibers. The soluble/insoluble fiber ratios of the fiber-rich diets used in this study were 0.30 for oat bran and 0.14 for wheat bran. Therefore, the oat bran-enriched diet presents a 2 -fold higher capacity than 


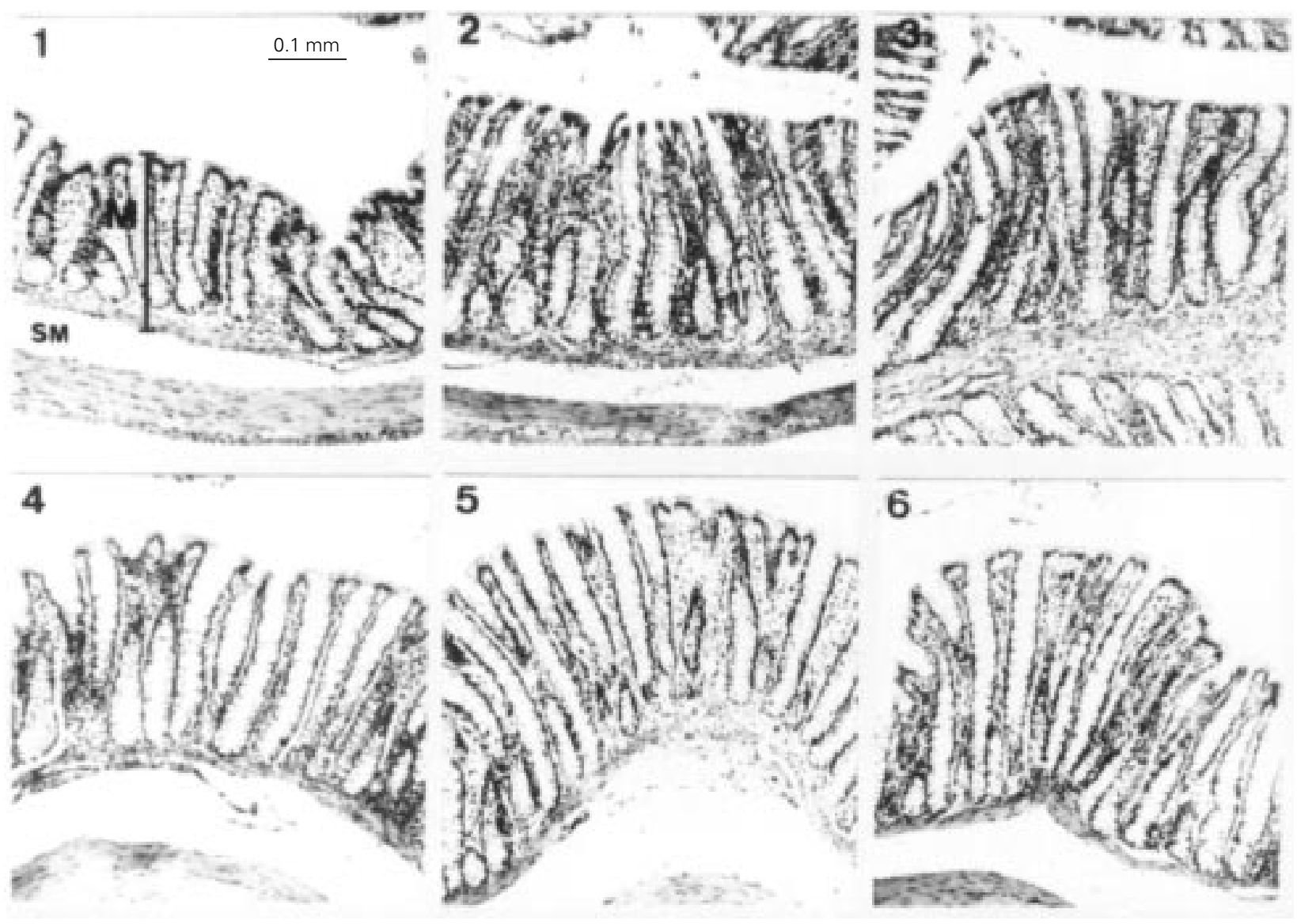

Figure 2 - Photomicrographs of the colon mucosa from mature (1, 2 and 3) and aged (4,5 and 6) rats fed a control diet (1 and 4) or diets enriched with oat bran (2 and 5) or wheat bran (3 and 6). The tissues were prepared as described in Material and Methods and stained with hematoxylin and eosin (X100). The mucosal height is indicated by the vertical bar. The horizontal magnification bar corresponds to $0.1 \mathrm{~mm}$. M, Mucosa; SM, submucosa.

the wheat bran-enriched diet for the production of SCFA.

Jacobs and White (28) showed that in rats fed wheat bran (20\% dietary supplementation) for 9 weeks there is decreased exfoliation and cell migration in the cecum, whereas cell proliferation and cell migration increase in the colon. Indeed, wheat bran did present a significant effect on the large intestine mucosa which was clearly more pronounced than that of oat bran (Table 2 and Figures 1 and 2). Whether these changes are due to decreased exfoliation and cell migration or to increased cell proliferation and cell migration remains to be investigated. This effect of wheat bran was observed in both newly weaned and aged rats. Similarly,
Goodlad et al. (29) showed that refeeding of 3-day starved rats with wheat bran-enriched diet causes a large proliferative response in the proximal, mid-, and distal colon. These findings led us to postulate that the changes in the large intestine epithelium induced by fiber-rich diets do not depend exclusively on the amount of short-chain fatty acids produced. In fact, wheat bran (a poor SCFA producer) did increase the mucosal height of the colon and cecum, whereas oat bran (a high SCFA producer) did not significantly affect the mucosa. Other factors may play a role in the present observations such as an increase in the motility and blood flow of the intestine, and secretion of enterohormones. 


\section{Acknowledgments}

The authors are grateful to Dr. E.A. Newsholme for constant encouragement and to W.M.S. Nunes, G. de Souza, J.R. Mendonça and M. Carnelós Filho for technical assistance.

\section{References}

1. A Report of the Royal College of Physicians (1980). Medical Aspects of Dietary Fibre. Pitman Medical, London, 93-139.

2. Sircar $B$, Johnson LR \& Lichtenberger LM (1983). Effect of synthetic diets on gastrointestinal mucosal DNA synthesis in rats. American Journal of Physiology, 244: G327-G335.

3. Jacobs LR \& Lupton JR (1984). Effect of dietary fibers on rat large bowel mucosal growth and cell proliferation. American Journal of Physiology, 246: G378-G385.

4. Dowling $\mathrm{RH}$, Riecken EO \& Laws JW (1967). The intestinal response to highbulk feeding in the rat. Clinical Science, 32: 1-9.

5. Bergmann EN (1984). Energy contributions of volatile fatty acids from the gastrointestinal tract in various species. Physiological Reviews, 70: 567-590.

6. Pell JD, Johnson IT \& Goodlad RA (1995). The effects of and interactions between fermentable dietary fiber and lipid in germfree and conventional mice. Gastroenterology, 108: 1745-1752.

7. Sakata $T$ (1984). Short-chain fatty acids as the luminal trophic factor. Canadian Journal of Animal Science, 64: 189-190.

8. Binder JH \& Mehta P (1989). Short-chain fatty acids stimulate active sodium and chloride absorption in vitro in the rat distal colon. Gastroenterology, 96: 989-996.

9. Galfi P, Neogrady S \& Kutas F (1991). The inhibitory action of sodium butyrate on the growth of KB, MMT and RPMI cells. Veterinary Research Communications, 15: 261-269.

10. Vecchia MG, Arizawa S, Curi R \& Newsholme EA (1992). Propionate inhibits cell proliferation in culture. Cancer Research Therapy and Control, 3: 15-21.

11. Curi R, Bond JA, Calder PC \& Newsholme EA (1993). Propionate regulates lymphocyte proliferation and metabolism. General Pharmacology, 24: 591-597.

12. Scheppach $W$, Bartram HP \& Richter $F$ (1995). Role of short-chain fatty acids in the prevention of colorectal cancer. European Journal of Cancer, 31A: 1077-1080.
13. Friedel D \& Levine GM (1992). Effect of short-chain fatty acids on colonic function and structure. Journal of Parenteral and Enteral Nutrition, 16: 1-4.

14. Stark AH \& Madar Z (1993). In vitro production of short-chain fatty acids by bacterial fermentation of dietary fiber compared with effects of those fibers on hepatic sterol synthesis in rats. Journal of Nutrition, 123: 2166-2173.

15. Scheppach W (1994). Effects of short chain fatty acids on gut morphology and function. Gut, 1: S35-S38.

16. Demigne C \& Remesy C (1985). Stimulation of absorption of volatile fatty acids and minerals in the cecum of rats adapted to a very high-fiber diet. Journal of Nutrition, 115: 53-60.

17. Kamath PS, Hepfner MT \& Phillips SF (1987). Short-chain fatty acids stimulate motility of the canine ileum. American Journal of Physiology, 253: G427-G433.

18. Goodlad RA, Lenton W \& Ghatei MA (1987). Proliferation effect of 'fiber' on the intestinal epithelium: relationship to gastrin enteroglucagon, and PYY. Gut, 28: 221-226.

19. DeRobertis FR, Craven PA \& Saito R (1984). Bile salt stimulation of colonic epithelial proliferation. Journal of Clinical Investigation, 74: 1614-1624.

20. Heerdt BG, Houston MA \& Augenlicht LH (1994). Potentiation by specific shortchain fatty acids of differentiation and apoptosis in human colonic carcinoma cell lines. Cancer Research, 54: 3288-3293.

21. Hague A, Elder DJ, Hicks DJ \& Paraskeva C (1995). Apoptosis in colorectal tumour cells: induction by the short-chain fatty acids butyrate, propionate and acetate and the bile salt deoxycholate. International Journal of Cancer, 60: 400-406.

22. Calabresse $C$, Venturini $L$, Ronco G, Villa P, Chomienne C \& Belpomme D (1993). Butyric acid and its monosaccharide ester induce apoptosis in the HL-60 cell line. Biochemical and Biophysical Research Communications, 195: 31-38.
23. Folino M, Mclntyre A \& Young GP (1995). Dietary fibers differ in their effects on large bowel epithelial proliferation and fecal fermentation-dependent events in rats. Journal of Nutrition, 125: 1521-1528.

24. Hague A, Manning AM, Hanlon KA, Huschtscha LI, Hart D \& Paraskeva C (1993). Sodium butyrate induces apoptosis in human colonic tumour cell lines in a p53-independent pathway: implications for the possible role of dietary fibre in the prevention of large-bowel cancer. International Journal of Cancer, 55: 498-505.

25. Heruth DP, Zirnstein GW, Bradley JF \& Rothberg PG (1993). Sodium butyrate causes an increase in the block to transcriptional elongation in the c-myc gene in SW837 rectal carcinoma cells. Journal of Biological Chemistry, 268: 2046620472.

26. Parekh D, Saydjari R, Ishizuka J, Townsend Jr CM \& Thompson JC (1992). Sodium butyrate stimulates polyamine biosynthesis in colon cancer cells. Surgical Oncology, 1: 315-322.

27. Curi R, Costa Rosa LFBP, Yano M Homem de Bittencourt Jr PI, Bond J \& Newsholme EA (1994). The effect of propionate on lipid metabolism in rat lymphocyte. General Pharmacology, 25: 14111416.

28. Jacobs LR \& White FA (1983). Modulation of mucosal cell proliferation in the intestine of rats fed a wheat bran diet. American Journal of Clinical Nutrition, 37: 945953.

29. Goodlad RA, Lenton W, Ghatei MA, Adrian TE, Bloom SR \& Wright NA (1987). Effects of an elemental diet, inert bulk and different types of dietary fibre on the response of the intestinal epithelium to refeeding in the rat and relationship to plasma gastrin, enteroglucagon, and PYY concentrations. Gut, 28: 171-180. 